http://dx.doi.org/10.5209/rev_ARAB.2015.v15.n3.48641

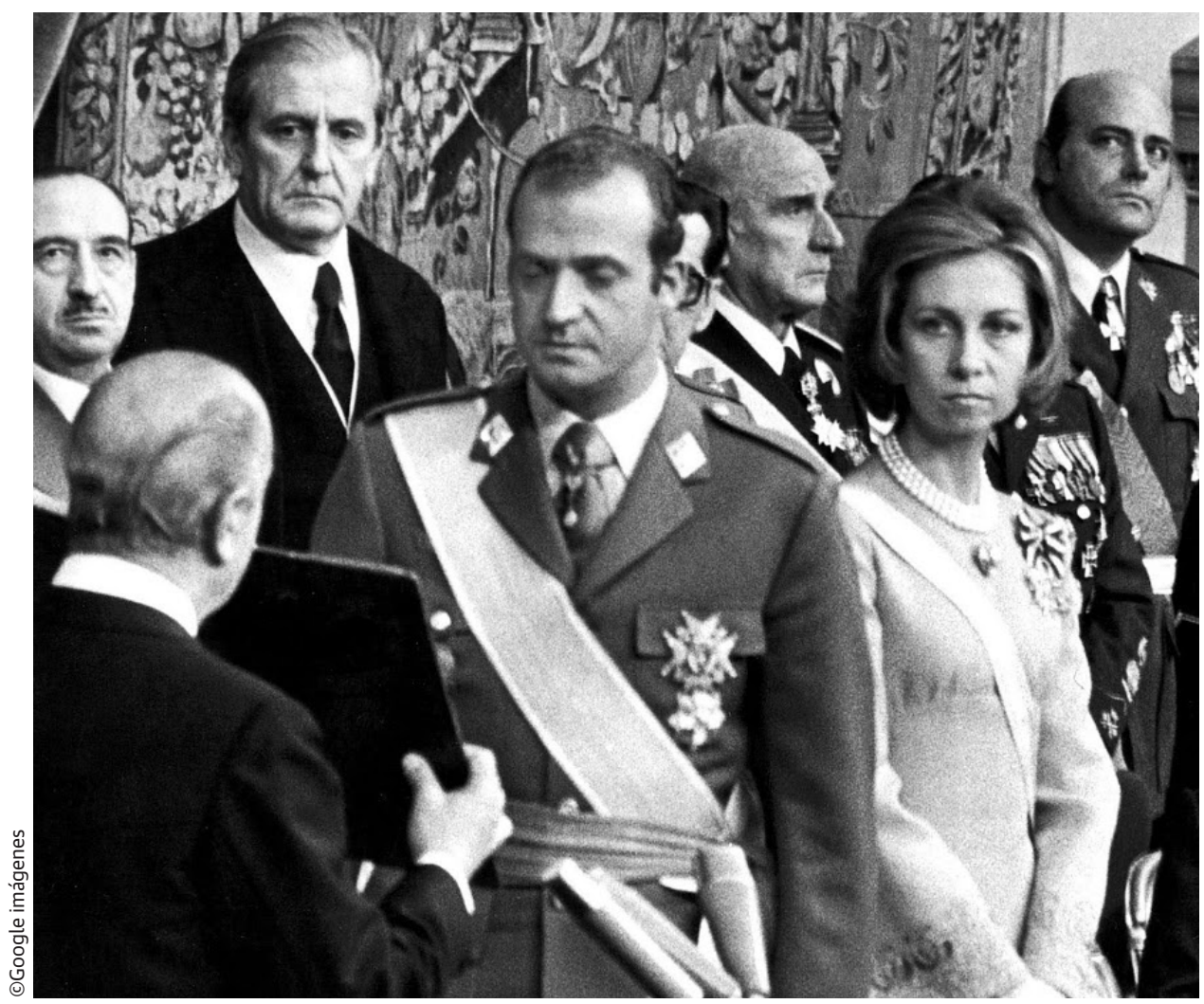

\title{
LA TRANSICIÓN, ¿UN MITO CREADO POR Y PARA LA TELEVISIÓN?
}

SPANISH TRANSITION TO DEMOCRACY, A MYTH CREATED BY AND FOR TELEVISION?

Bénédicte Brémard / benedicte.bremard@gmail.com UNIVERSITÉ DE BOURGOGNE 


\section{RESUMEN}

Este artículo considera las representaciones de la Transición democrática española propuestas por la televisión en España desde 1995 hasta hoy. Sin pretender la exhaustividad, analiza tanto la recuperación como la recreación de escenas y figuras que ya pertenecen a la Historia estando todavía presentes en la memoria colectiva. El análisis de algunos programas, tanto de ficción como de información, nos permitirá esbozar una cartografía de las representaciones televisivas de la Transición. Veremos cómo se organizan en términos de formatos y géneros televisivos (series y miniseries, biopics o thrillers políticos), cómo se inscriben en la filiación de otros programas anteriores o al revés, cómo intentan deconstruir el mito televisivo de la Transición forjado a lo largo de sus innumerables representaciones televisivas. También nos preguntaremos hasta qué punto dicho mito, elaborado a partir del extraordinario fondo de archivo de imágenes televisivas de la Transición, llega a esconder la realidad histórica más que a revelarla. Todos estos mecanismos están muy lejos de concernir tan sólo al universo de la pequeña pantalla, su calendario específico y sus particulares modos de producción, creación y difusión. Nos permiten percibir, más de 40 años después del inicio de este proceso, la permanencia de memorias conflictivas, de cuestiones tabúes y la ausencia de un imaginario colectivo consensual y sereno sobre el período. Las imágenes del (o sobre el) pasado, si no nos proporcionan grandes revelaciones sobre el pasado, sí que resultan elocuentes sobre el presente y su complicada relación con la Historia reciente.

PALABRAS CLAVE

Transición democrática española, televisión, mito, memoria, series, biopic, Cuéntame cómo pasó, 23-F, Audiencia abierta, Operación Palace.

\section{ABSTRACT}

This article deals with the representations of Spanish transition to democracy shown by television in Spain from 1995 to nowadays. Without claiming to be exhaustive, it analyses the recycling as well as the re-creating of scenes and figures which already belong to History although they are still present in collective memory. The analysis of a few fictional and informative programmes will enable us to sketch out a cartography of the representations of the transition on television. We will see how they get organized around TV formats and genres (series and mini-series, biopics and political thrillers), how they are related to other previous programmes or, on the contrary, how they attempt to deconstruct the television myth of the transition built up with its innumerable television representations. We will also wonder to which extent such a myth, drawn up from the amazing archives collection of TV pictures of the transition, comes to hide historical reality rather than disclose it. All these mechanisms are far from concerning only the small screen and its specific schedule and modes of production, creation and broadcasting. They enable us to perceive the persistence of conflicting memories, of taboo subjects and the lack of a consensual, dispassionate collective imagination over this period, more than 40 years after the beginning of this process. The pictures from (or about) the past, if they do not bring great revelations to us about the past, turn out to be meaningful about the present and its complicated relationship with recent History.

KEYWORDS

Spanish transition to democracy, television, myth, memory, series, biopics, Cuéntame cómo pasó, 23-F, Audiencia abierta, Operación Palace.

Recibido: 15 de marzo de 2015 Aceptado: 12 de octubre de 2015 


\section{INTRODUCCIÓN}

La historia de la Transición es una historia actualizada y memorizada al mismo tiempo por la televisión, desde el asesinato de Carrero Blanco hasta el intento de golpe de estado del 23-F, pasando por las primeras elecciones generales y la victoria de quien fue director general de TVE, Adolfo Suárez. Desde 1995 hasta hoy, desde la serie documental de Victoria Prego hasta el programa de propaganda monárquica Audiencia abierta, se observa una constante operación de reciclaje y recreación de archivos tanto en programas informativos o documentales como en la ficción. Los actores de la Transición, anónimos o famosos (la familia de clase media de Cuéntame cómo pasó, el Rey, Suárez, Tarancón, etc.) se convierten en protagonistas de series de una transición mitificada y dramatizada. Este proceso plantea el problema de la representación ficticia de una época y unas figuras todavía muy presentes en la memoria colectiva audiovisual al mismo tiempo que sorprende constatar cómo un período marcado por el "pacto de silencio" se convirtió en el mito más mediatizado de la Historia de España. Intentaremos esbozar un panorama de dicho material, destacando tres modalidades distintas de las representaciones televisivas: la dramatización del archivo, la relectura de fechas o figuras claves del pasado reciente en términos de géneros filmicos como el thriller político o el biopic y, por último, los procesos de mitificación y mistificación ${ }^{1}$ de la Transición presentes en programas informativos con fines propagandísticos o contra-propagandísticos en busca de la captación comercial o ideológica de la audiencia.

\section{LA DRAMATIZACIÓN DEL ARCHIVO: DE "LA TRANSICIÓN" A "CUÉNTAME CÓMO PASÓ"}

La Transición, serie documental de trece capítulos emitida por primera vez en TVE entre julio y octubre de 1995, sin duda fue la pionera y matriz de las demás creaciones televisivas que vamos a presentar. Recordemos que se elaboró a partir de imágenes de archivo y testimonios de los protagonistas de la época, acompañados por la voz en off de Victoria Prego, y retrataba la evolución política entre el asesinato de Carrero Blanco (en diciembre de 1973) y las elecciones democráticas de junio de 1977, siguiendo pues un esquema de crónica documental. De hecho, Cuéntame cómo pasó, pese a ser una ficción, reivindicó desde sus comienzos dicha herencia, contando con la participación de Victoria Prego en un capítulo especial, "Háblame de ti", que concluía la emisión de la primera temporada. La periodista aparecía primero en un falso campo/contracampo, integrada en imágenes de archivo de Franco en el Azor, luego guiando al espectador en los distintos decorados de la serie y, por último, entrevistando a los principales actores.

Con trece años de programación y de éxito, tanto a nivel de audiencia como de reconocimiento por parte de la crítica audiovisual ${ }^{2}$, Cuéntame... ya es parte de la historia de la televisión en España y por supuesto, también ocupa un lugar destacado en la historia de las representaciones de la Transición democrática. De éxito a fenómeno social, la serie se ha convertido finalmente en una especie de institución cuya última consagración ha sido la integración de una secuencia suya al lado de las más populares series británicas (como EastEnders) en uno de los cuadros de la ceremonia de apertura de los Juegos Olímpicos de Londres en $2012^{3}$. Recordemos que ésta fue puesta en escena por el cineasta Danny Boyle, cuyo gusto por la cultura popular y el reciclaje de referencias son famosos.

Esta abundante materia de estudio (unos 272 capítulos repartidos en 15 temporadas 4 que cubren el período histórico desde 1968 hasta 1983) ofrece un ejemplo de evolución inédito dado que traduce tanto los cambios de la época representada como los de la época de difusión.

\footnotetext{
1 Entenderemos aquí el mito como "una creación imaginaria que accede a la realidad tomando forma"

2 Sigue reuniendo a varios millones de telespectadores y fue adaptada en Portugal e Italia. Para un estudio más detallado, véanse nuestros trabajos mencionados en la bibliografía.

3 Véase al respecto http://www.rtve.es/television/20120727/ cuentame-como-paso-serie-olimpica/550811.shtml (página consultada en enero de 2015).

4 La 16a temporada está a punto de estrenarse mientras estamos escribiendo estas líneas.
} 
Asimismo, se puede observar una evolución de la estrategia de escritura. Gracias a unos intercambios con los guionistas que estuvieron presentes desde el origen de la serie, Eduardo Ladrón de Guevara y Patrick Buckley ${ }^{5}$, pudimos identificar algunos de dichos mecanismos.

En sus primeras temporadas la señal de identidad de Cuéntame... es sin lugar a dudas el uso que hace de las imágenes de archivos de la Transición, evidenciado por los títulos de crédito $^{6}$, temporada tras temporada y por la compra de un televisor por la familia protagonista desde el primer capítulo, frente al cual veremos de manera recurrente a la familia siguiendo las noticias mientras comen. Según lo que nos explicó Ladrón de Guevara, el punto de partida de la escritura del guión es un trabajo de documentación, cercano al del periodista (o del historiador) que consiste en determinar para cada temporada cuál es el material de archivo del que dispone TVE7 y cómo dramatizar la actualidad de la época integrando la trama familiar en ésa.

A nivel formal, este proceso se traduce en las primeras temporadas de la serie por una figura recurrente que los directores llaman chroma key y que también podríamos llamar efecto Forrest Gump: la espectacular incrustación de los personajes de la familia Alcántara dentro de

5 Recogidos en parte en nuestros trabajos mencionados en la bibliografía.

6 Incluyen imágenes de archivo que cambian según las temporadas de la serie y el período representado en cada una de éstas así como numerosas alusiones a la imagen: personajes grabando a su entorno con pequeñas cámaras, un plano de un proyector, del reflejo del niño en el agua, o incluso de la "nieve" que invade la pantalla del televisor.

7 Un rápido vistazo al historial de Cuéntame..., cuyos capítulos están todos en línea en la página que se le dedica en la web de $T V E$, permite comprobar que el ritmo es muy desigual y depende de la abundancia (o escasez) de los fondos de archivo, dependiendo éstos de los acontecimientos históricos. Así, entre las $5 a$ et 6 a temporadas se pasa de golpe de julio de 1971 al otoño de 1972 y luego entre las 6a y 7a temporadas de finales de 1972 al otoño de 1973, con elipsis que revelan "tiempos muertos" (desde un punto de vista dramatúrgico) de la Historia del tardofranquismo. Al revés, el asesinato de Carrero Blanco es objeto de tres capítulos seguidos (112, 113 y 114), igual que la muerte de Franco $(152,153$ y 154). Algunos capítulos además se presentan como docudramas (véase por ejemplo el capítulo 152 dirigido por Cecilia Bartolomé, en el que se ve a la familia Alcántara contestando las preguntas de una periodista sobre lo que opinan que pasará después de la muerte del dictador, y que incluye también testimonios de políticos o periodistas que vivieron la época). las imágenes de archivo de los últimos años de la dictadura, al lado de sus protagonistas históricos. Aparentemente, esta figura podría hacer de la familia protagonista no sólo testigos sino actores de una página de la historia de España que se estaba escribiendo. También podría dar lugar a la recuperación de la memoria audiovisual de la dictadura, que fue monopolizada por el poder franquista mediante el NO-DO, órgano oficial de información o, mejor dicho, de propaganda. Sin embargo, al estudiar las ocurrencias de dicha figura, parece que en realidad las posibilidades que ofrece no siempre son explotadas, dado que estas yuxtaposiciones de personajes de la ficción/personajes de la realidad histórica se colocan las más veces al nivel del sueño o de la fantasía, dicho de otro modo, son meras imágenes mentales de los personajes. En estas imágenes, el dictador aparece más ridículo que verdaderamente temible ${ }^{8}$, quizás porque para el español de a pie no tenía existencia palpable (mucho menos que su policía por ejemplo). Involuntariamente, Cuéntame... representa, más que la Transición, la dificultad a representar un período de la Historia actual desde el punto de vista del ciudadano medio ${ }^{9}$.

Al fin y al cabo, Cuéntame... ilustra esta reflexión de Michel Serceau a propósito de las series sobre Historia que son, según él "extraordinarios documentos sobre el estudio de las representaciones sociales y de las mentalidades":

"Son susceptibles de revelar ciertos aspectos de las imaginaciones del momento. Pueden, en este sentido, reflejar la psique colectiva. Lo pueden tanto más cuanto que la vida social y el trabajo vienen, en general, menos descritos que la vida privada. Siendo problematizado el individuo, estos géneros proporcionan una especie de representación "psicosocial" de la historia. ${ }^{10 "}$

8 Véase nuestro artículo: "L'image de la dictature dans le feuilleton Cuéntame cómo pasó", in Image et pouvoir (Actes du 4è Congrès international du GRIMH, 18-20 novembre 2004), Université Lumière-Lyon II, 2006, p. 601-609.

9 Es interesante, de hecho, la evolución que notamos respecto a las principales figuras políticas de la época: Franco aparece a través de las imágenes del No-Do y muchas veces en sueños o fantasías de los personajes. Suárez, quizás mucho más presente enla memoria de los telespectadores adultos, dado que siempre $\rightarrow$ 
En efecto, cada personaje representa un arquetipo (cuando no un estereotipo), una actitud (y la de toda una generación) distinta frente a la Transición. La abuela es una figura ambigua que vive en el miedo de la Guerra Civil pero también guarda su memoria; el estudiante comprometido, abogado y luego periodista (el que más se encuentra en el corazón de los eventos), representa la generación de los guionistas, mientras que el turbulento benjamín (aunque dada la duración de la serie ya no traduce la mirada cándida de un niño) es de la misma generación que el productor; el padre de familia es el típico votante de centro deseoso de mantener la paz familiar y su autoridad, mientras que las mujeres (madre e hija) reivindican su libertad, sea mediante el trabajo sea mediante la vida sentimental. En cuanto a los exiliados, su condición es vivida como un drama y un fracaso y no como una verdadera alternativa.

A fin de cuentas, este retrato de la familia media española bajo la Transición se presenta como un mito unificador. Es evidente que la meta de la serie es llegar a la audiencia, por eso la nostalgia o el humor, el happy end (incluso inverosímil, véase la "resurrección" del hijo mayor al que se creía muerto al final de la $15^{a}$ temporada) se prefieren a un desenlace violento o angustioso. Por la misma razón, la serie peca a menudo de anacrónica a través de diálogos impensables en boca de los personajes años antes de la Transición. Este desfase entre el conocimiento histórico y el discurso unificador de la serie revela a pesar suyo la permanencia del conflicto cultural: lo que está en juego son las dos memorias de la dictadura y la Transición ${ }^{11}$. Entre estas dos memorias, la elegida por la serie es una memoria proustiana, un recuerdo más sensitivo que significativo o reflexivo, un recuerdo de pequeños detalles cotidianos que "momifica el cambio"12. También es debido a la forma elegida, la de la crónica. Como explica Michel Serceau, este género toma como materia la Historia al mismo tiempo que la niega o va en su contra:

"Inscribiéndose en contra del fresco así como del biopic, la crónica es interesante en la medida en que hace -o pretende hacer- saltar tanto el ocultador del personaje como el de la historia cronológica. Dando a ver, no sólo la vida cotidiana, como se suele decir en una primera lectura, sino también el contexto económico, o incluso en los mejores casos, el contexto cultural, dando a ver las superestructuras y no sólo las estructuras, la crónica introduce o reintroduce quizás al sujeto trascendido, amputado o sublimado por el fresco o la hagiografía. [...] Pero [este avatar de la película histórica] se inscribe al mismo tiempo en contra del historicismo y en contra de la representación de las hazañas y de las gestas fundadoras, en contra de la sacralización de las instituciones. ${ }^{13 "}$

$\rightarrow$ cuidó inteligentemente su imagen pública, aparece encarnado por un actor pero siempre de manera fugaz, de espaldas por ejemplo en los capítulos 198 y 261. Santiago Carrillo llegó a participar en el rodaje del capítulo 178, dando una supuesta entrevista clandestina a Toni en diciembre de 1976, aunque por razones obvias de verosimilitud de edad, sólo se oía su voz y se divisaba su silueta. Por último, Juan Carlos I es el gran ausente de la serie. Aparece casi menos que Franco, como una figura lejana convocada solamente a través de archivos de momentos excepcionales como el 23-F. El estudio comparativo de dicho tratamiento de las figuras históricas muestra que la serie crea su propia jerarquía en el imaginario colectivo sobre la Transición.

10 "Ces genres sont susceptibles de donner à voir certains aspects des imaginations du moment. Ils peuvent, en ce sens, refléter la psyché collective. Ils le peuvent d'autant mieux que la vie sociale et le travail y sont généralement moins décrits que la vie privée. L'individu y étant problématisé, ces genres donnent de l'Histoire une sorte de représentation 'psychosociale'", SERCEAU Michel. Le Mythe, le miroir et le divan, Presses Universitaires du Septentrion, Lille, 2009, p. 26 (traducción nuestra).

11 Cabe precisar que este diálogo pasado representado/presente de representación se hace muchas veces a través del fondo cultural. Por ejemplo, en el capítulo 80 emitido en 2004, Antonio descubre durante un viaje a Rusia la experiencia de un "niño de Rusia", que fue exiliado voluntariamente por su familia (republicana) para escapar de la Guerra Civil; este caso es uno entre los muchos que sacó a la luz el documental de Jaime Camino estrenado en 2001. Del mismo modo, en el capítulo 150, Herminia alude al destino trágico de "Las Trece Rosas", probablemente poco conocido en el momento de la acción (1975), pero familiar para el espectador dado que la película de Emilio Martínez Lázaro (2007) todavía estaba en cartelera en el momento de difusión de dicho capítulo de Cuéntame... Entre 2004 y 2011, bajo los dos mandatos de Zapatero, cambió de manera radical el discurso, recordándonos que la serie refleja la línea editorial de la televisión pública en la que se emite. En el capítulo 148, Antonio y su hermano hablan de la necesidad de justicia para las víctimas de la Guerra Civil así como de un perdón colectivo mientras se recogen ante una fosa común justo después del anuncio del infarto de Franco (octubre de 1975). Este diálogo hace evidentemente eco al debate sobre la Ley de Memoria Histórica debatida en las Cortes en el momento de difusión (noviembre de 2007). Pasa lo mismo con las alusiones a la crisis económica a la que alude el capítulo 235, situado a principios de los 1980 y emitido en 2013. Y el diálogo entre personajes y espectadores de la serie es más extraño aún cuando es silencioso, como al final del capítulo 224, cuando después de pronunciar en off (y con su voz de hoy) estas palabras, Carlos rompe las convenciones narrativas mirando a la cámara: "Aquel mismo día el presidente de la Junta Andaluza dejó su huelga de hambre. Y poco después se celebró un referéndum que no contentó a nadie pero marcó el $\rightarrow$ 
En este sentido, podemos preguntarnos si la crónica no sería el mejor modo de proponerle al español medio un lugar como protagonista de la Transición, un lugar que ejerció muy pocas veces y con un margen de maniobra muy limitado (el referéndum o las elecciones), dado que fue excluido del proceso y de los pactos que lo rigieron. De este modo, sin hacer ni el proceso de la Transición ${ }^{14}$, ni siquiera el del franquismo, la serie le propone indirectamente al telespectador una revisión de sus propias circunstancias socio-políticas y de las mutaciones actuales. Involuntariamente, nos enseña pues tanto o incluso más sobre el presente que sobre "el despertar de un tiempo que nos cambió" como dice la canción.

\section{DE ACTORES DEL CAMBIO POLÍTICO A HÉROES DE SERIES}

El período de la Transición se caracterizó por la producción de series que hacían propaganda de los cambios sociales de manera directa (pense-

\footnotetext{
$\rightarrow$ camino para el nacimiento de la Comunidad Autónoma Andaluza. La nueva España se estaba forjando, y es que el cambio histórico era imparable. Como imparable era mi propia autonomía. Lo más fácil, dejar la carrera, ya estaba hecho. Y ahora tenía que encontrar la forma y el momento para decírselo a mi padre. Todo cambio crea desconcierto, y a decir verdad, yo estaba bastante confundido, a todos los niveles."

Este capítulo se emitió el 10 de noviembre de 2011, 10 días antes de las elecciones que marcaron la vuelta de la derecha al poder. La confusión de Carlos parece en sintonía con la del espectador.

12 "La momification du changement", expresión de André BAZIN citado por COMPANY RAMON Juan Miguel. "Un espacio nacido en el tiempo : Proust y lo proustiano en el cine", in Metodologías de análisis del film, (Actas del I Congreso de Análisis fílmico, GÓMEZ TARÍN Francisco Javier, MARZAL FELICI Javier, eds.), Edipo, Madrid, (10-12 de noviembre de 2005), 2007, p. 153-170.

13 "S'inscrivant en faux aussi bien contre la fresque que contre le biopic, la chronique est intéressante en ceci qu'elle fait - ou prétend faire - sauter le cache aussi bien du personnage que de l'histoire événementielle. Donnant à voir, non seulement la vie quotidienne, comme on le dit dans une lecture trop courte, mais aussi le contexte économique, voire, dans les meilleurs des cas, le contexte culturel, donnant à voir les superstructures et pas seulement les structures, la chronique introduit ou réintroduit peutêtre le sujet transcendé, amputé ou sublimé par la fresque ou l'hagiographie. (...) Mais [cet avatar du film historique] s'inscrit en même temps en faux contre l'historicisme et contre la représentation des grands faits et gestes fondateurs, contre la sacralisation des institutions", SERCEAU Michel. Étudier le cinéma, Éditions du Temps, Paris, 2001, p. 171-172.

14 Véase al respecto el análisis que proponía Alfonso Guerra (fecha de mayo de 2010): http://www.rtve.es/alacarta/videos/ television/alfonso-guerra-habla-sobre-los-sectores-que-opinan-que-hay-que-revisar-transicion/761398/, página consultada en enero de 2015.
}

mos en casos como Anillos de oro' ${ }^{16}$ y la Ley de Divorcio, Segunda enseñanza ${ }^{17}$ y la Ley Orgánica de Derecho a la Educación) o de los cambios políticos de manera indirecta, recurriendo a la metáfora de viejas contiendas como Los desastres de la guerra.

$\mathrm{Al}$ revés, en los últimos años se multiplicaron las ficciones televisivas del período; si empezaron en clave de conmemoración, con $20 \mathrm{~N}$ Los últimos días de Franco dirigida por Roberto Bodegas y emitida en Antena 3 el 20 de noviembre de 2008, pronto seguida por tres producciones alrededor del 23-F, 23-F, el día más difícil del rey (miniserie de dos capítulos dirigida por Silvia Quer y emitida en TVE en 2009), 23-F. Historia de una traición dirigida por Antonio Recio y emitida en Antena 3 en 2009 también, aunque centrada en la trama (ficticia) de amistad y traición entre dos militares, y 23-F, la película (dirigida por Chema de la Peña y estrenada en 2011, que podemos incluir porque contó con la participación de TVE ${ }^{17}$ ); el enfoque de la primera, que considera el 23-F como fecha clave en la biografía del rey Juan Carlos I dejaba prever la ola de reconstituciones y biopics que vino después. Dicha ola conllevó otra miniserie de dos capítulos titulada Adolfo Suárez, retrato de un presidente, dirigida por Sergio Cabrera y emitida en 2009 por Antena 3; Tarancón, el quinto mandamiento, dirigida por Antonio Hernández y protagonizada por José Sancho, emitida en TVE en 2011; Sofía, dirigida por Antonio Hernández y emitida por

15 La serie, estrenada en TVE en octubre de 1983, se escribió y rodó poco después de la aprobación de la reforma del Código Civil que introducía el divorcio (1981). En ella, se abordan también otras cuestiones delicadas en el momento como el adulterio, la homosexualidad o el aborto.

16 Ésta combinaba dicho interés por parte de la guionista y actora Ana Diosdado al interés del gobierno del PSOE por defender la Ley Orgánica de Derecho a la Educación, examinada por el Tribunal Constitucional mientras se gestaba la serie, como explica Concepción CASCAJOSA VIRINO en "Un nuevo modelo educativo en la televisión de la transición española: Segunda enseñanza de Ana Diosdado", in Image et éducation, Actes du 7è Congrès international du Grimh, Le GRIMH/Passages XX-XXI, Université Lumière-Lyon 2, 2011, p. 239-248. 17 De hecho, su carrera en las salas fue muy modesta según la Base de Datos de películas calificadas del MCU, contó con Espectadores: 60.876 Recaudación: 371.204,84€ (http://www.mecd.gob.es/cultura-mecd/areas-cultura/cine/industria-cine/calificacion/base-datos-peliculas-calificadas.html, página consultada en octubre de 2015). 
Antena 3 en 2011, El asesinato de Carrero BlanCo, dirigida por Miguel Bardem y emitida en TVE en diciembre de 2012, o la más reciente Sofía, dirigida por Antonio Hernández y emitida por Antena 3 en 2011, El asesinato de Carrero Blanco, dirigida por Miguel Bardem y emitida en TVE en diciembre de 2012, o la más reciente El Rey (dirigida por Norberto López Amado y emitida en Telecinco en octubre-noviembre de 2014).No deja de sorprender semejante abundancia de ficciones sobre la historia actual y, sobre todo, de representaciones de figuras históricas de la Transición cuando o bien están todavía vivas, o bien su imagen sigue muy presente en la memoria de los telespectadores porque pertenecen a un período reciente que fue objeto de grabación televisiva como acabamos de ver. En este panorama, podemos distinguir dos tendencias:

1) La elevación de dichas figuras políticas al rango de héroes, líderes, hombres providenciales, combinada con la humanización de estas figuras; colocadas en momentos claves de dilemas, en los que el espectador siente empatía con sus emociones, se muestran a la altura de las circunstancias todavía muy vivas en la mente del espectador; éste sería el caso de $23-F$, el día más difícil del rey, Adolfo Suárez y Tarancón y dicha recuperación se corresponde con elementos contextuales. Así, como señala José Carlos Rueda Laffond a propósito del trato dado a la figura de Suárez en la miniserie televisiva:

"Su recuperación simbólica comenzó a consagrarse a partir de 1996, momento en que se produjo el reconocimiento institucional a su legado mediante la concesión del Premio Príncipe de Asturias a la Concordia. Además, se vio reforzado por otras dos circunstancias: por un lado, por los trágicos sucesos familiares y personales sufridos por el expresidente; y por otro, por la estrategia del Partido Popular (PP) de reclamar la necesidad de una "segunda transición", en vísperas de su triunfo electoral. Este discurso pretendía capitalizar el recuerdo idealizado de los años 1976-1979, el referente sociológico del centro político y la propia figura de Suárez, entendido como arquitecto de la democracia española (Aznar). Con posterioridad, su recuerdo ha sido enaltecido desde otras vertientes ideo- lógicas, tal y como lo refleja la obra de Javier Cercas, Anatomía de un instante. ${ }^{18 "}$

2) Al revés, la reconstrucción minuciosa que estiliza los acontecimientos históricos inspirándose en los géneros de la época y su estética, en particular el cine policíaco y negro de los años 1970, lo que desemboca en el thriller político según el director de 23-F, la película. Sería más bien el caso de esta película, que multiplica los enfoques sobre los hechos, logrando de este modo que el protagonista sea la acción y no los personajes. Comienza con Tejero saliendo de casa la mañana del 23-F y termina también con Tejero saludado por los miembros de su grupo de insurgentes. Es el caso también de El asesinato de Carrero Blan$\mathrm{CO}^{19}$, que usa el split-screen a modo de guiño estético al cine de los años 1970, y que logra filmar de manera original la famosa explosión del coche presidencial, con una focalización subjetiva desde el coche de los guardaespaldas del presidente, haciendo olvidar la espectacular escena una y otra vez recuperada de la película Operación Ogro (Gillo Pontecorvo, 1979).

Para ilustrar dichas diferencias de óptica, podemos comparar dos secuencias sacadas de dos ficciones sobre el mismo acontecimiento, es decir 23-F. El día más difícil del Rey y 23-F, la película, dado que dichas secuencias recrean la misma escena de la llamada del Rey a su padre don Juan de Borbón en las primeras horas del golpe. $\mathrm{Si}$ ambas ficciones reproducen una misma escena histórica, lo hacen con estéticas totalmente distintas. La primera nos ofrece un verdadero melodrama, con un rey cuya actitud no tiene nada de majestuosa (está sentado y le vemos abati-

\footnotetext{
18 RUEDA LAFFOND, José Carlos. "Adolfo Suárez y Felipe y Letizia: ficción televisiva y memorias inmediatas sobre la monarquía española", Hispanic Review (autumn 2011), University of Pennsylvania Press, p. 639-660.

19 Cabe reconocer que algunas de estas producciones quedan algo difícil de clasificar. 20N, los últimos días de Franco parece oscilar entre el melodrama de la agonía del dictador, al que se presenta como un anciano débil y enfermizo (no deja de sorprender la elección de Manuel Alexandre para interpretar el papel) y el thriller político médico que intenta demostrar cómo el futuro rey iba preparando la Transición mientras el dictador era víctima del ensañamiento de los médicos, presionados por parte del "búnker" por mantenerle en vida.
} 
do y llorando mientras la música en off subraya el patetismo de la escena) sino que se presenta ante todo como un hijo desorientado que recurre a su padre en busca de apoyo. Los diálogos insisten repetidamente en el doble sacrificio (de connotación bíblica), el del padre (que renunció al trono) y el del hijo (que se crió a distancia de su familia por voluntad de Franco a cambio de la corona). En cuanto a la segunda, se conforma con reproducir una escena numerosísimas veces descrita por historiadores y cronistas (incluyendo el famoso despertar del príncipe heredero para que pudiera vivir aquella prueba iniciática), dejando, si podemos decirlo así, al Rey en el papel del rey y a don Juan en la sombra mediante la voz fuera de campo.

Parece claro que a través de estas dos tendencias estéticas, se enfrentan dos propósitos: por un lado, el de rehabilitación de ciertas figuras algo maltratadas por la historia: en el caso de Tarancón, basta con leer algunas editoriales de Enrique Miret Magdalena en Triunfo para darnos cuenta de que distaba mucho de ser una figura consensual, sino alguien cuyas posturas no hacían la unanimidad, ni entre el clero, ni entre la izquierda. El caso de Suárez es un caso ejemplar de líder carismático y maestro de la comunicación (no por nada había sido director general de TVE) durante los primeros años de su carrera política. Es sabido que su segundo mandato lo convirtió en chivo expiatorio de la moribunda UCD y causó su caída en el olvido después de su dimisión en 1981 y hasta la recuperación de su figura que empieza con su desaparición del escenario político a causa de la enfermedad de Alzheimer y culmina con funerales y homenajes dignos de un rey en marzo de 2014. En este caso, es evidente que a través del homenaje oficial la corona buscó recuperar parte del prestigio perdido a partir de 2012 con el accidente del Rey en Botsuana, el caso Nóos y otros escándalos muy mediatizados. Pero podemos constatar que la representación televisiva no lo puede todo: ya se sabe la degradación que conoció la imagen del Rey hasta su abdicación en junio de $2014^{20}$, mientras que el fervor popular se expresó claramente durante los funerales de Suárez, dejando claro que una y otra figura no estaban tan unidas en el imaginario colectivo sobre logros y fracasos de la Transición y demostrando quizás que en la memoria colectiva no hay héroes sino muertos.

Por otro lado, los episodios violentos y las numerosas zonas de sombra de la historia de la Transición (como los papeles de cada uno en la conspiración del 23-F o la posible intervención de la CIA en el asesinato de Carrero Blanco), representan una inagotable fuente de inspiración para guionistas y directores (algo así como el asesinato de Kennedy y el 11-S para la historia de los EEUU), lo que prueba que constituyen eslabones claves de la lenta construcción de la Transición como mito fundacional -para bien o para mal- de la identidad de España. De modo que, a medida que van desapareciendo los actores de la época y que la memoria va convirtiéndose en Historia, se cumple una trayectoria opuesta en la que las imágenes televisivas se multiplican, contribuyendo a la construcción de nuevos mitos del imaginario (y por ende, del recuerdo) colectivo. Curiosamente, tanto una como otra tendencia limitan mucho el recurso a imágenes de archivo que, en general, permanecen en los márgenes del relato ficticio (títulos de crédito iniciales o incluso finales) como meras huellas del carácter histórico de la ficción. Eso sí, la ficción puede servirle al archivo de promoción (y viceversa), dado que en su mayoría, dichas ficciones se ven programadas antes de documentales que vuelven, mediante testimonios y archivos, sobre las figuras evocadas.

Del mismo modo, una serie como Cuéntame... también incluye unos capítulos con forma de docudramas sobre los momentos más destacados del período evocado, así como un poten-

20 "En el año 2004 el 84\% de los españoles tenía una opinión excelente del rey, mientras que sólo un $3,6 \%$ de los encuestados se pronunciaron en contra de su figura; diez años después, el $62 \%$ de los españoles pedía la abdicación de Juan Carlos, según la encuesta de Sigma Dos para El Mundo" (datos citados en GONDRA AGUIRRE, Ander, G. DE ANGELIS, Marina, LOPEZ DE MUNAIN, Gorka, VIVES-FERRANDIZ SANCHEZ, Luis (Grupo de Investigación Irudi). Cuando despertó, el elefante todavía estaba ahí. La imagen del Rey en la Cultura Visual 2.0, Sans Soleil Ediciones, Barcelona, 2014, p. 144). 
cial enorme de productos derivados (CD, libros, etc), que fomentan, a través de la web de TVE, la interactividad con el público (por ejemplo con la posibilidad de voto por la interpretación de la canción título). La puesta en línea sistemática y cronológica de los capítulos de todas estas series viene pues a alimentar el catálogo de imágenes sobre la Transición y dar testimonio de sus constantes relecturas. La tipología que vamos esbozando muestra pues que no hay fronteras entre las categorías de representaciones de la Transición, sino al revés, constantes pasarelas de unas modalidades a otras.

Por lo tanto, en este proceso, cabe destacar una tercera modalidad de relectura televisiva de la Transición, la que proponen los programas de información. Últimamente hemos podido observar dos tendencias completamente opuestas respecto al trato de la Transición: por un lado, el intento de romper con una herencia pesada que se manifiesta paradójicamente en la recuperación de viejos formatos de programas; y por otro lado, la desaparición de las fronteras entre información y ficción de entretenimiento, o la confusión entre montaje y desmontaje del mito.

\section{LA TRANSICIÓN, DEL MITO QUE VENDER AL MITO QUE VENDE}

\section{1 "Audiencia Abierta", cel No-Do de la monarquía?}

Emitido desde el 13 de octubre de 2012 todos los sábados a las 13:30 h. en TVE 1, y con más de cien programas hasta el día de hoy, Audiencia Abierta se autopresentaba de la manera siguiente en su primera emisión:

"Durante 30 minutos, cada sábado en La 1 y a esta misma hora, repasaremos las actividades del rey como jefe del estado y del príncipe de Asturias, su sucesor al frente de la primera institución del país. La actualidad, la información contextualizada y la reflexión presidirán un programa de clara vocación divulgativa. Como ocurre con el parlamento o las instituciones europeas, Audiencia abierta, también concebido como programa de servicio público, abre un hueco en la parilla para la jefatura del estado. Pretendemos, cumpliendo un mandato parlamentario, abrirle puertas para acercar la institución a los ciudadanos. Queremos pura y simplemente informar, nada más. Huiremos del sensacionalismo y la frivolidad, pero buscaremos un producto ameno y atractivo. Será un formato austero y sencillo, acorde con los tiempos. Eso sí, apostaremos por el rigor y la objetividad."

A continuación, el sumario de la $1^{\mathrm{a}}$ edición anunciaba reportajes sobre:

- La fiesta nacional marcada por la crisis económica y el debate soberanista en Cataluña,

- La nueva limitación de representación de la Casa Real en actos institucionales a los reyes y los príncipes de Asturias.

- La austeridad como regla en la celebración de la fiesta nacional.

- Unas declaraciones del Príncipe sobre la lucha contra el paro juvenil.

- La definición del papel del rey como jefe del Estado según la Constitución.

- Y la comparación con otra monarquía parlamentaria, la de Gran Bretaña.

Pese a las declaraciones de intención del principio, resulta difícil no darse cuenta de que cada reportaje, si bien está vinculado con la actualidad oficial salvo las dos últimas secciones, reitera una y otra vez el mismo mensaje poco o nada subliminal de propaganda promonárquica, por no decir explícitamente felipista más que juancarlista. Y es que el año 2012 no sólo fue el de escándalos en serie para la monarquía, sino también el arranque de un intento de dorar la imagen de la monarquía y de manera más general, de España: además de la aparición de Audiencia abier$t a$, notamos que la fundación FIES retomará en 2013 la publicación de la revista España real, abrirá perfiles en Facebook y Twitter ${ }^{21}$, mientras que es en 2012 cuando se crea por Real Decreto el Alto Comisionado del Gobierno para la Marca España, un cargo para la promoción de la imagen exterior de España que por muchos aspectos recuerda el "España es diferente" del tardofranquismo ${ }^{22}$. Así, en el primer reportaje, nos enteramos de que "Por primera vez en los últimos años 
el desfile del día de la fiesta nacional transcurrió sin protestas." Se insiste en el hecho de que el rey no habló "de las aspiraciones soberanistas lideradas por el presidente de la Generalitat”, según el autor del reportaje "para evitar motivos de desencuentro después de su famosa carta en la página web de la Casa Real escenificada en su encuentro en Barcelona con Artur Mas" mientras que el reportero repite palabra por palabra la declaración del príncipe: "Cataluña no es un problema (...). Hay que rebajar las tensiones y caminar todos en la misma dirección y son los políticos que deben arreglarlo, también las instituciones deben contribuir. Reconoce que el ambiente electoral no favorece pero confía en que pasadas las elecciones, las cosas vuelvan a la normalidad." Dicho de otro modo, el Rey creó la polémica cuando el príncipe se muestra como garante de la paz y el consenso. Un esquema que puede recordar el de los albores de la Transición y muestra el uso contradictorio y casi involuntario que hace el programa de la memoria y que explicaremos luego.

Durante el reportaje sobre la definición del papel del rey según la Constitución, el comentario de la periodista parece curiosamente profético, dado que, sobre unas imágenes de los reyes con los príncipes de Asturias, observa que "hay otras voces que, aun reconociendo el buen funcionamiento del sistema, recuerdan que faltan desarrollos legislativos en casos como la abdicación, la regencia o la incapacidad del rey, también señalan que hay aspectos que se pueden mejorar" y termina declarando que la constitución de las cámaras en el arranque de la última legislatura (en presencia del Rey largamente aplaudido por los diputados) "dejó imágenes para el recuerdo". Parece otra manera de pasar página al reinado de Juan Carlos I.

21 Véase GONDRA AGUIRRE, Ander, G. DE ANGELIS, Marina, LOPEZ DE MUNAIN, Gorka, VIVES-FERRANDIZ SANCHEZ, Luis (Grupo de Investigación Irudi). Op. cit., p. 142-143.

22 Véanse : www.marcaespana.es, CARO, Antonio. "Arriba (la marca) España", Periódico Diagonal, 08/08/2013, https://www. diagonalperiodico.net/saberes/arriba-la-marca-espana.html, JlMENEZ GOMEZ, Isidro. "Sol, playa y aviones militares para vender "Marca España", Periódico Diagonal, 08/05/2013, https://www. diagonalperiodico.net/saberes/sol-playa-y-aviones-militares-para-vender-marca-espana.html, consultadas en enero de 2015.
El último reportaje insiste en los detalles menos complacientes de la monarquía británica, como para señalar que en comparación con ésta los españoles no se pueden quejar. La periodista destaca que: "La británica es la monarquía europea más cara, la cifra oficial del coste del último año es de 32,3 millones de libras, unos 40 millones de euros, pero esa cifra no incluye por ejemplo los gastos de seguridad que son elevados. Según los activistas del grupo Republic el coste real alcanza los 200 millones de euros". Y termina mencionando especulaciones sobre una abdicación del príncipe Carlos, "el príncipe heredero más viejo de la historia" a favor del príncipe Guillermo "mucho más popular”. Respecto al tema que nos interesa, cabe subrayar que cada emisión del programa incluye una sección histórica-didáctica sobre el papel del Rey desde la Transición, en el caso de esta primera emisión, con archivos de declaraciones del Rey y también de Santiago Carrillo, Adolfo Suárez, Felipe González, Manuel Fraga, que le expresan su reconocimiento por haber instaurado un régimen democrático y no haber ejercido nunca el heredado poder absoluto.

Estamos pues ante una peculiar memoria de la Transición porque ésta es vista desde un futuro muy próximo que hay que vender. Por un lado, se trata de apostar por la figura del entonces futuro rey (Felipe VI) y de ensalzar la labor de Juan Carlos I, pero dejando cuidadosamente sus méritos en el pasado y limitándolos al período de la Transición, como si fuese su mayor y más consensual éxito. Por otro lado, el programa no hace sino recordar involuntariamente que la Historia de la monarquía española se parece a una eterna repetición, con un heredero de la corona en el que pocos creen y una imagen del poder que hay que vender como, a la vez, una garantía de estabilidad política y paradójicamente, una ruptura con el antecesor en la función de jefe de Estado. En este sentido, la TVE de hoy sigue funcionando con los mismos métodos que ya se habían expresado a través de TVE o del No-Do en los años 1970; respecto a una serie de reportajes dedicados a los viajes de los entonces Príncipes 
de España, José Carlos Rueda Laffond destaca "el énfasis dado al respaldo popular y (...) la casi total neutralización de la figura de Franco ${ }^{23}$ ”. De modo que intentando modernizar la imagen de la corona, Audiencia abierta no hace sino recordar su linaje con la dictadura.

\section{2 "Operación Palace", cel mito (des)mitificado?}

El 23 de febrero de 2014, La Sexta emite, en el horario habitual de Salvados, un programa presentado como documental dirigido por Jordi Évole y titulado Operación Palace. A través de varias entrevistas de figuras políticas de la época, así como periodistas e historiadores, acompañadas por imágenes de archivo y apoyándose, según lo que afirma la voz en off, en documentos secretos revelados por la CIA, el programa explica cómo el 23-F fue montado por el gobierno de Adolfo Suárez, con el acuerdo de los principales dirigentes de la oposición, del Rey y de la Casa Blanca y con el fin de despertar el consenso alrededor de la monarquía y la Constitución en un período de crisis. Habría sido puesto en escena por el cineasta José Luis Garci (entrevistado también), viéndose éste recompensado posteriormente por el Óscar para su película Volver a empezar. Hasta la dimisión de Suárez habría sido consecuencia de este montaje, por permitir un pleno en el Congreso y un intento de golpe más espectacular. Las imágenes de archivo cobran nuevo sentido mediante el montaje o la voz en off: se crea así la sospecha alrededor de una misteriosa caja blanca presente en las apariciones del Rey, de una frase inacabada de Suárez durante una entrevista, de cómo el locutor de cadena SER pudo identificar a Tejero como "un teniente coronel" pese a la distancia a la que se encontraba, e incluso se interpretan detalles de los diálogos de Volver a empezar como alusiones veladas al golpe escenificado por Garci. Sólo en los últimos minutos del programa se revela el carácter falso del conjunto, a través de una inscripción en la pantalla, leída por la voz en off, que explica:

\begin{abstract}
"Nos hubiese gustado contar la verdadera historia del 23-F. Pero no ha sido posible. El Tribunal Supremo no autoriza la consulta del sumario del juicio hasta que hayan transcurrido 25 años desde la muerte de los procesados o 50 años desde el golpe. Esta decisión es tierra abonada para teorías y fabulaciones de todo tipo... Como ésta. Posiblemente la nuestra no será la última ni la más fantasiosa."
\end{abstract}

Los títulos de crédito también vienen acompañados de breves intervenciones de los entrevistados, dando su opinión sobre el aspecto entretenido y didáctico del programa. Algunos subrayan el valor revelador de dicha ficción esperpéntica declarando que "Muchas veces la ficción dice más sobre una cosa que la propia realidad" o aludiendo a "la verdad de las mentiras", o la necesidad de desacralizar el 23-F. Lo cierto es que el programa consiguió records de audien$\mathrm{cia}^{24}$ y se convirtió en tema de polémicas en la prensa y las redes sociales, hasta llegar a una denuncia ${ }^{25}$ rechazada por la Federación de Asociaciones de la Prensa Española. La misma FAPE calificó Operación Palace como "un reportaje televisivo que pertenece a un ámbito que está más allá del periodismo, y que no debe someterse a sus principios (...) un programa que pretende provocar y experimentar, que transgrede lo convencional (...) una patraña cuyo objetivo no es engañar al público, sino obtener audiencia”. La polémica suscitó comparaciones entre Jordi Évole y su programa y Orson Welles con La guerra de los mundos ${ }^{26}$. El periodista se defendió de haber desprestigiado o restado credibilidad al

23 RUEDA LAFFOND, José Carlos. "Entre Franco y Juan Carlos. representación y memoria en televisión y otros medios populares (1966-1875), Historia Actual Online, www.historia-actual.org, N³2 (otoño 2013), p. 93-105.

24 23,9\% de cuota de pantalla y 5,2 millones de espectadores según varias fuentes de prensa, pero sobre todo picos de más de $73 \%$ de share social en Twitter y demás redes sociales.

25 Presentada por el presidente de la Asociación de Usuarios de la Comunicación, Alejandro Perales. Todos estos datos aparecen en la web de la cadena http://www.lasexta.com/especiales/operacion-palace-23-F/ (página consultada en enero de 2015).

26 En realidad, Évole afirma haberse inspirado en el falso documental Opération lune (William Karel, Arte France, 2002). A diferencia de Operación Palace, se hizo montando fragmentos de entrevistas sacadas de su contexto, no con la complicidad de los entrevistados. 
periodismo haciendo notar: "parece que en esta profesión otros cuentan mentiras pero si no lo dices, no pasa nada". Esta atrevida operación de intento de desmitificación de un evento clave de la Transición (el 23-F) no hace sino aplicar una constatación ya expresada por Roland Barthes en su estudio sobre el mito: es muy difícil resistir al mito, salvo usando su recurrencia, su increíble supervivencia, de modo que "la mejor arma contra el mito, quizás sea mitificarlo a su vez, producir un mito artificial (...) Dado que el mito roba lenguaje, ¿por qué no robar el mito?27”

\section{A MODO DE CONCLUSIÓN: DEL OLVIDO A LA DESMEMORIA, LAS IMÁGENES DE UNA TRANSICIÓN "MARCA ESPAÑA"}

La representación audiovisual de la historia actual plantea, de manera general, varias cuestiones. Primero, la de la verdad histórica frente a la verosimilitud televisiva. La forma serial, que implica cierta dilatación y repetición, y el uso de imágenes de archivo tienden a producir lo que podríamos llamar "verdades cansadas" o estereotipos $^{28}$. Los estudios de Jesús González Requena sobre televisión demostraron que entre verdad y espectáculo, la televisión no sólo elige siempre el espectáculo sino que lo reivindica como arma de seducción; Gérard Imbert demostró a su vez el paso de la televisión de la era de lo espectacular a la era de lo especular ${ }^{29}$. Dicho de otro modo el medium televisivo es sumamente narcisista y no para de nutrirse de sus propias imágenes. La ficción histórica televisiva busca

27 "La meilleure arme contre le mythe, c'est peut-être de le mythifier à son tour, c'est de produire un mythe artificiel (...). Puisque le mythe vole du langage, pourquoi ne pas voler le mythe ?", BARTHES, Roland. Mythologies, Éditions du Seuil, Paris, 1957, p. 209, traducción nuestra.

28 Curiosa ironía, en Cuéntame..., el personaje del padre, Antonio (Imanol Arias) trabaja en una imprenta en las primeras temporadas, y como recuerda Michel Serceau, la palabra estereotipo viene del lenguaje de la imprenta: "es vinculada con la noción de reproducción; implica la idea que la reproducción edulcora el significado y la riqueza del original" ("il est lié à la notion de reproduction ; il induit l'idée que la reproduction édulcore le sens et la richesse de l'original", SERCEAU Michel. Étudier le cinéma, Éditions du Temps, Paris, 2001, p. 35-36, traducción nuestra).

29 Véase bibliografía recrear un sabor evocador, capaz de hacer emerger el recuerdo en el telespectador. Un recuerdo real o fantaseado por los que no vivieron la época, a base de imágenes o tópicos vinculados con la Transición, ora sacados de imágenes de la realidad, ora de imágenes de anteriores creaciones.

Al mismo tiempo, tanto la ficción como la información televisiva sobre la historia actual juegan sobre la complicidad con el telespectador y el reconocimiento de los acontecimientos para construir relatos clásicos cuya función es triple: movere, placere, docere. Al ver todas estas imágenes, uno se da cuenta de que la realidad de la Transición (piénsese en el 23-F o en los escándalos que oscurecieron los últimos años del reinado de Juan Carlos I) resulta mucho más esperpéntica que cualquiera de las fantasías creadas al respecto. También cabe recordar que, aún más que las películas, los programas de televisión son obras colectivas que dependen de los recursos (económicos e ideológicos) proporcionados por los canales que los coproducen y emiten.

Por lo tanto, la creación televisiva no genera historia o historiografia, sino que, a su manera, selectiva, fragmentaria e influenciada por ideologías diversas, participa de la elaboración de una memoria colectiva que, al reducir la Historia a sus imágenes, corre el riesgo de fabricar más olvido que memoria, o al menos, lo que en psicoanálisis se llama recuerdos-pantallas, recuerdos que tienen más cosas que esconder que cosas que revelar, pero que también pueden enseñarnos muchas cosas sobre las voluntades que obran a la construcción identitaria de España como democracia, los muros de tabúes que levantaron, y las grietas de resistencia que encuentran ${ }^{30}$.

30 Dos observaciones pueden ilustrar este aspecto: la primera se refiere a las censuras (que se apoyan en los artículos 490-491 de la Constitución) a caricaturas del Rey o del Príncipe: "El argumento era -y es- claro: si nos reímos del rey dañamos nuestra frágil democracia. Pero, entonces, ¿qué democracia es esta en la que no podemos reírnos del rey ?", GONDRA AGUIRRE, Ander, G. DE ANGELIS, Marina, LÓPEZ DE MUNAIN, Gorka, VIVES-FERRANDIZ SÁNCHEZ, Luis (Grupo de Investigación Irudi). Op. cit., p. 98; la segunda defiende el derecho a fabular de Operación Palace: "Se le puede reprochar al programa que no fuera más brillante en la elaboración de su mentira, que levantara un aparato de falsedad más indescifrable, pero sostener que Évole pierde para el futuro la credibilidad periodística es tan disparatado como acusar de malos padres a quienes cantamos aquel Vamos a contar mentiras, tralalá a nuestros hijos. [...] Si alguien tiene ganas de tomarse en serio $\rightarrow$ 


\section{BIBLIOGRAFÍA}

BRÉMARD, Bénédicte. "Cuéntame la crónica de tiempos revueltos: experimentar la verdad histórica mediante la ficción televisiva", comunicación para el Congreso Tramas de la verdad, V Congreso de Análisis Textual (Valencia 7-9 de noviembre de 2007), Trama y Fondo, $n^{\circ} 24$, primer semestre 2008, p. 141-149.

BRÉMARD, Bénédicte. "L'image de la dictature dans le feuilleton Cuéntame cómo pasó", in Image et pouvoir (Actes du 4è Congrès international du GRIMH, 18-20 novembre 2004), Université Lumière-Lyon II, 2006, p. 601-609.

BRÉMARD, Bénédicte. "Les représentations de la résistance dans Cuéntame cómo pasó", in Regards n8 (CHAPUT Marie-Claude, SICOT Bernard, éds.), Université Paris X-Nanterre, Centre de Recherches Ibériques et Ibéro-américaines, Groupe de Recherches Résistances et Exils, 2005, p. 225-237.

BRÉMARD, Bénédicte. "Les stéréotypes à la télévision: feuilleton d'aujourd'hui sur l'Espagne d'hier", in ¿Verdades cansadas? Imágenes y estereotipos acerca del mundo hispánico en Europa, (BERGASA Víctor, CABAÑAS Miguel, LUCENA GIRALDO Manuel, MURGA Idoia, éds.), Madrid, CSIC, 2009, p. 615-625.

CASCAJOSA VIDRIO, Concepción. "La chica de ayer: memoria y desmemoria televisivas de la Transición en España", Journal of Spanish Cultural Studies, Routledge, Vol. 13, N³, 2012, p. 260-275.

CASTELLO, Enric, LOPEZ, Francisca (eds). Cartografías del 23-F. Representaciones en la prensa, la televisión, la novela, el cine y la cultura popular, Laertes, Barcelona, 2014.

COMPANY RAMON, Juan Miguel. "Un espacio nacido en el tiempo: Proust y lo proustiano en el cine", en Metodologías de análisis del film, (Actas del I Congreso de Análisis fílmico, GÓMEZ TARÍN, Francisco Javier, MARZAL FELICI, Javier, eds.), Edipo, Madrid, (10-12 de noviembre de 2005), 2007, p. 153-170.

CORONADO RUIZ, Carlota, RUEDA LAFFOND, José Carlos. La mirada televisiva. Ficción y representación histórica en España, Fragua, Madrid, 2009.
CUETO ASIN, Elena, GEORGE, David R. Jr, LOPEZ, Francisca (eds). Historias de la pequeña pantalla Representaciones históricas en la televisión de la España democrática, Iberoamericana Vervuert, Madrid, 2009.

ELIADE, Mircea. Aspects du mythe, Gallimard, Paris, 1963.

GONDRA AGUIRRE, Ander, G. DE ANGELIS, Marina, LOPEZ DE MUNAIN, Gorka, VIVES-FERRANDIZ SANCHEZ, Luis (Grupo de Investigación Irudi). Cuando despertó, el elefante todavía estaba ahí. La imagen del Rey en la Cultura Visual 2.0, Sans Soleil Ediciones, Barcelona, 2014.

GONZALEZ REQUENA, Jesús. El discurso televisivo : espectáculo de la posmodernidad, Cátedra, Madrid, 1999.

HUERTA FLORIANO, Miguel Ángel, SANGRO COLON, Pedro (eds.). De 'Los Serrano' a 'Cuéntame'. Cómo se crean las series de televisión en España, Arkadin, Madrid, 2007.

MEDINA, Mercedes (coord). Series de televisión. El caso de 'Médico de familia', 'Cuéntame cómo pasó' y 'Los Serrano', Ediciones Internacionales Universitarias, Madrid, 2008.

PALACIO, Manuel (ed.). El cine y la transición política en España [1975-1982], Biblioteca Nueva, Madrid, 2011.

$\mathrm{POHL}$, Burkhard. "Mémoire vivante, mémoire médiatisée? Le recyclage des années 70", in Cinémaction: Mémoire du cinéma espagnol (1975-2007), (FEENSTRA Pietsie, éd.), $\mathrm{n}^{\circ} 130,2009$, p. 116-122.

POHL, Burkhard. "'Hemos cambiado tanto'. El tardo franquismo en el cine español", en Cine, nación y nacionalidades en España (BERTHIER Nancy, SEGUIN JEAN-Claude, eds.), Casa de Velázquez, Madrid, (12-14 de junio de 2006), 2007, volume 100, p. 217-231.

SERCEAU, Michel. Étudier le cinéma, Éditions du Temps, Paris, 2001.

SERCEAU, Michel. Le Mythe, le miroir et le divan, Presses Universitaires du Septentrion, Lille, 2009.

\footnotetext{
$\rightarrow$ el 23-F debería indignarse por esa cantinela, habitual en cada aniversario del golpe, que crece y crece sin unos mínimos de rigor y bien lejos de la maravillosa salud mental que propone lo confesadamente falso. [...] [Operación Palace] es un guiño a la construcción de nuestro país, infinitamente más ambicioso que todas las reacciones airadas, las apropiaciones de la verdad y las versiones iluminadas que llevamos 33 años padeciendo.", TRUEBA, David. "Contar mentiras", El País, 27/02/2014, www.elpais.com, página consultada en enero de 2015.
} 